\title{
Review of N. Emrah Aydinonat's The invisible hand in economics: how economists explain unintended social consequences. London/New York: Routledge, 2008, 272 pp.
}

\author{
MARK BLAUG \\ Amsterdam School of Economics
}

This is a splendid book about a controversial concept in economics, the notion that there may be unintended benevolent social consequences of actions undertaken by individuals for entirely private reasons and that these consequences are not merely benevolent but are capable of producing an order that appears to be designed although it is actually the product of spontaneous action. I say it is a controversial concept in economics, but in reality it has been only too eagerly adopted by economists and domesticated as part and parcel of modern general equilibrium theory à la Arrow and Debreu.

The word but not the concept of the invisible hand was of course invented by Adam Smith who had an inkling, but only an inkling, of the modern version of the doctrine in the form of the First Fundamental Theorem of welfare economics, namely that every competitive equilibrium achieves a Pareto-optimal allocation of resources (Blaug, 2008). Emrah Aydinonat follows Emma Rothschild in sorting out the checkered role of Adam Smith in the genesis of the Invisible-Hand Doctrine, carefully distinguishing Smith's process interpretation from the modern end-state interpretation of the final result of the invisible hand (Aydinonat 2008, 68-81, 88-91).

He further explores the role of the Invisible-Hand Doctrine in economics with a critical discussion of Menger's much praised use of it in explaining the emergence of money, showing that while the origin of commodity money may be the unintended social consequence of private action, it is doubtful that fiat money is likewise the unintended consequence of dispersed private action (pp. 27-48); in any case, Menger never fully explicated the mechanism for the spontaneous co-ordination of individual money holding. Menger's story is depicted as a possible explanation of the emergence of money, but by no means a complete or even a fully convincing account. 
Similarly, Thomas Schelling's checker-board model of racial segregation of urban housing as a result of the mild preference of some citizens for living near people like themselves is discussed as a paradigmatic example of an invisible-hand explanation of a social phenomena, which nevertheless is only a partial explanation of the phenomena of urban segregation falling well short of a total explanation (pp. 50-97). This may well be the fault of all models in social science, a subject the author explores in two interesting chapters on the philosophy of science (pp. 119-134), including the role of game theory in modelling behaviour in economics (pp. 149-169).

This brings us back to the fundamental distinction between end-state models and process models. According to end-state models, we are told a great deal about the nature of equilibrium once we have reached it, but almost nothing except hand-waving about how we actually reach it. The same is true of many invisible-hand explanations, such as those of Menger on the origin of money, Schelling on residential segregation, and game-theoretic explanations of Nash equilibria (pp. 159-164). Even when all players have common knowledge of each other's rationality and even when their beliefs are consistently aligned, there are always multiple Nash equilibria in any indefinitely repeated game-this is so well known that it has been called a folk theorem of game theory. What it means is that to explain how individuals select their optimal strategies in social interactions, we have to go outside game theory, and that of course is one of Emrah Aydinonat's messages in these final chapters on the philosophy of science.

This is a book that cannot fail to provoke thoughtful reactions from its readers about the potentialities of explanation in economics.

\section{REFERENCES}

Aydinonat, N. Emrah. 2008. The invisible hand in economics: how economists explain unintended social consequences. London and New York: Routledge [INEM series].

Blaug, Mark. 2008. The Invisible Hand. In The New Palgrave Dictionary of Economics, eds. S. N. Durlauf, and L. E. Blume. London: Palgrave Macmillan, Vol. IV: 564-566.

Mark Blaug has made valuable contributions across a whole range of fields, including history of economics, methodology of economics, and economics of education and the arts. He is affiliated to the Amsterdam School of Economics, and honorary member of EIPE, Erasmus University. Contact e-mail: <m.blaug@gmail.com> 